Article

\title{
Incentive Decision for Supply Chain with Corporate Social Responsibility and Lag Effect
}

\author{
Huijin Cheng * $*$ and Hao Ding \\ School of Economics and Management, China University of Petroleum, Qingdao 266580, China; \\ dinghao6666@163.com \\ * Correspondence: b17080192@s.upc.edu.cn; Tel.: +15215328876
}

Received: 1 March 2020; Accepted: 23 March 2020; Published: 25 March 2020

\begin{abstract}
With the deepening of economic globalization and international division of labor, enterprises gradually turn to supply chain management methods that aiming at win-win cooperation. An enterprise's corporate social responsibility (CSR) behaviors will affect the interests of other enterprises in the supply chain through transmission, diffusion, amplification, feedback, etc. Therefore, scholars are currently focusing on helping supply chain enterprises to take social responsibility. This paper takes a two-echelon supply chain as an example, which is composed of one manufacturer and one retailer. Considering the influence of lag effect on the performance level of corporate social responsibility, we discuss the optimal strategy of corporate social responsibility in supply chain under centralized and decentralized decision-making. Three incentive models are proposed to improve the implementation effect of decentralized supply chain decision. Study finds that, in real life, decentralized supply chain is more in line with the decision-making mode of supply chain participants, even though centralized decision-making has better operation effect. Under certain circumstances, the mixed contract, which is composed of advertising cooperation, cost sharing and revenue sharing, could lead to supply chain coordination. As an external stakeholder, the government's subsidy plays a positive role in promoting the fulfillment of corporate social responsibility. Multi-subsidy performs better than single-subsidy. Although the time lag promotes the manufacturer's social responsibility efforts and the retailer's advertising, it somehow compromises overall profit of the supply chain. Therefore, manufacturers should try to reduce the lag effect to maintain the overall profitability of the supply chain.
\end{abstract}

Keywords: lag effect; corporate social responsibility; goodwill; differential game; incentive decision

\section{Introduction}

Since the second half of the 20th century, corporate social responsibility (CSR) has been a wide concern of governments, international organizations, and the public. Frequent incidents caused by absence of social responsibility, such as the BP oil spill in the Gulf of Mexico, the Tianjin Binhai New Area explosion, various food safety concerns, and production safety accidents, have caused adverse effects in society. Enterprises tend to pay more attention to the performance of social responsibility and extend social responsibility to their operation and management of supply chain, seeking cooperation among enterprises in the supply chain. One of supply chain enterprises' social responsibilities is to integrate social responsibility of chain members. Enterprises run in a certain supply chain system, and each node of the supply chain will affect the social responsibility practice level of the entire chain. Because member enterprises in the supply chain have different strength levels, their understanding and implementation levels of corporate social responsibility are also different. In order to improve the practice level of social responsibility in the whole supply chain, it is necessary for supply chain enterprises to cooperate with each other to fulfill social responsibility. Enterprises should 
find a coordination point between social responsibility and economic benefits to promote the further development of supply chain corporate social responsibility. As an organization of external supply system, the government has inherent advantages. Governments' compulsory behavior is an important force to promote the fulfillment of social responsibility in a supply chain. However, government often fails to play a strong role in supervision and incentive in reality, which weakens the external governance of supply chain social responsibility. Therefore, how to strengthen the external incentive role of supply chain social responsibility has certain research significance.

The concept of CSR was first put forward by Sheldon in 1924. Sheldon believes that the social responsibility of industrial management needs to consider social and human factors [1]. This concept was formally brought forward in 1953. Bowen first comprehensively discussed business ethics and social responsibility. He believes that businessmen should make decisions and carry out business activities according to the expectations of social goals and values [2]. With continuous enrichment and expansion of the theory of corporate social responsibility in the later period, a certain theoretical system has been gradually formed. From the initial consideration of only shareholders' interests, enterprises expand to consideration of other stakeholders' economic, social, and environmental interests. CSR is used as a strategic means for enterprises to increase profits and enhance competitive edges. The research focus in the field of CSR has gradually shifted from whether the enterprise should take social responsibility to how the enterprise should take social responsibility better. In the current context of international division of labor and cooperation, CSR concerns not only a single enterprise, but also the entire supply chain [3]. The social responsibility of supply chain enterprises is a focus of a sustainable supply chain, which is an innovation of management mode. It means that, while chasing profit maximization, a supply chain should also consider employees, upstream and downstream partners, consumers, communities, environment, and other stakeholders, and take the corresponding legal, economic, and ethical responsibilities. In this paper, supply chain enterprises' CSR performance could be reflected mainly in the product attributes. Product attributes here refer to improving satisfaction of customers and other enterprises in the supply chain through developing, producing, and selling products with high quality, high environmental protection, strong safety performance, and other CSR attributes.

In recent years, due to the importance of CSR, many scholars began to take CSR as a key factor in the operational decision-making of the supply chain. Dominating types of supply chain studied include two-echelon supply chain, three-echelon supply chain, and closed-loop (reverse) supply chain [4-8]. In order to achieve supply chain coordination and improve the performance level of CSR, supply chain enterprises will adopt some contractual methods to meet the needs of all parties, such as two-part pricing, revenue-sharing, cost-sharing [9-13]. Cruz (2013) proposed a comprehensive supply chain decision-making model based on CSR, trying to capture the potential supply chain disruption risk, social risk, and demand uncertainty risk in the supply chain [14]. Modak et al. (2019a) considered two kinds of CSR tools in the closed-loop supply chain, social work donation (SWD) and investment recovery. They proposed a mathematical model for maximizing expected profits under the carbon emission tax [6]. Modak et al. (2019b) analyzed the impact of closed-loop supply chain with CSR on environmentally friendly channel performance in the context of CSR practice [7]. Hosseini Motlagh et al. (2019a) considered the optimal pricing, sustainability level, and CSR decision of reverse supply chain under demand disruption [8]. Stranieri et al. (2019) studied the impact of CSR activities on the relationship restructuring of the food supply chain [15]. Hosseini Motlagh et al. (2019b) and Jokar et al. (2019) took CSR investment as an important decision-making in the context of supply chain, and analyzed the coordination of supply chain under scenario demand [4,5].

Combing the above literatures, we find that CSR activities can not only reduce the potential supply chain disruption risk, social risk, and demand uncertainty risk in global supply chain operation, but also improve corporate reputation to increase the market demand of enterprises and bring long-term profits [16] Many scholars neglect the influence of corporate reputation on the performance of supply chain when they consider the decision-making of CSR. The change of CSR can predict the change 
of corporate reputation. Over time, it may encourage leaders to gain more benefits by continuously investing in CSR activities, so as to create sustainable competitive advantage [17]. In order to better improve the corporate reputation, many enterprises will also spread CSR through advertising, such as Walmart, Kroger, and other enterprises. Therefore, when discussing the decision-making of CSR in supply chain, this paper considers a dynamic change of corporate reputation, which mainly includes two factors, one is the level of CSR, the other is the strength of advertising. The change of corporate reputation is not immediate, and there is often a delay effect [18]. For example, in real life, the manufacturing industry plays a major role in fulfilling CSR. The social responsibility activities of manufacturing enterprises cover the research and development of product technology, low-carbon emission efforts, etc. This is a long-term and continuous process. Therefore, the current CSR investment will have a significant impact on the level of CSR of later products. Based on this, we try to set a delay time for CSR of the manufacturing industry to represent the delay effect of corporate reputation. Considering the influence of advertising on supply chain operation strategy, Taboubi (2017) studied the price and advertising coordination in bilateral monopoly from a dynamic perspective [19]. Buratto et al. (2019) coordinated the supply chain by studying the cooperative advertising plan and price discount mechanism [20]. Lu et al. (2019) proposed a dynamic advertising game in supply chain management [21]. Few scholars analyze the impact of advertising on corporate reputation, and then make the decision of CSR in the supply chain.

For the operation strategy of the supply chain considering government subsidies, most scholars choose to study green supply chain management. They discuss the carbon tax or emission reduction subsidy policies proposed by the government, and put forward the policy scheme that can maximize the environmental benefits. Hafezalkotob et al. (2016) set up the government as the main leader, implemented green subsidies and carbon tax subsidies to explore the impact of environmental policies on supply chain performance [22]. Zhang et al. (2017) analyzed the impact of three government policies on two competitive supply chains under decentralized or centralized decision-making [23]. Yi et al. (2019) believe that the subsidy policy can not only improve the level of energy conservation, but also reduce carbon emissions [24]. Only a few scholars design government subsidies in the social responsibility of supply chain enterprises. Arya et al. (2015) discussed the impact of CSR subsidies on the supply chain. As incentives are usually linked to market value, enterprises not only have additional incentives to achieve social goals (such as by donating inventory), but also incentives to increase the retail market price [25]. Liu et al. (2018) constructed a three-stage Stackelberg model for retailer-led decision-making of supply chain social responsibility under government subsidies. They used the model to analyze the optimal decision-making with and without government subsidies. The results show that, compared with nongovernmental subsidies, a certain range of government subsidies can promote supply chain members to assume social responsibility, improve the overall performance and social welfare of the supply chain [26]. In prior studies, most scholars consider the incentive role of supply chain CSR in a unidirectional way, while in real life, most supply chains involve both internal and external cooperation. This paper proposes a government subsidy -mixed-contract scenario to explore the internal and external collaborative decision-making of the decentralized supply chain.

In light of the past literatures, we found that scholars have taken CSR as an important reference factor in supply chain operation. To some extent, CSR can improve the performance of supply chain enterprises (Cater 2002; Chiou 2011) [27,28]. On the basis of considering the performance level of CSR, maximizing the profits of supply chain enterprises, to explore the decision-making of each node enterprise in the supply chain is the current research focus of scholars. Owing to the spillover effect problem in the process of fulfilling CSR, the establishment of selecting an incentive mechanism is necessary. However, most scholars choose closed-loop supply chain and green supply chain when considering the government incentive behavior. Few scholars consider the government subsidy into the supply chain CSR operation strategy, and analyze how to design the subsidy strategy to encourage the supply chain members to bear more CSR. In addition, advertising factors are concerned in the operation of green supply chain and reverse supply chain. Advertising effects can effectively improve 
the goodwill of enterprises, and then increase market share. However, few scholars take into account the influence of advertising effect on supply chain decision-making when the supply chain node enterprises perform their social responsibility behavior. At the same time, the impact of CSR on business reputation has a delayed effect. Dynamic analysis is more in line with the actual supply chain operation than static analysis.

Based on the above discussion, this paper establishes a two-echelon supply chain composed of one manufacturer and one retailer, and considers the impact of corporate reputation with delay effect on supply chain demand into supply chain decision-making. It dynamically analyzes the level of social responsibility and corporate reputation of the supply chain enterprises, and considers the decision-making of CSR in the supply chain in five scenarios: traditional centralized decision-making; traditional decentralized decision-making; decentralized supply chain internal cooperation decision-making under mixed contract; decentralized supply chain external cooperation decision-making under government subsidy; and decentralized supply chain internal and external cooperation decision-making under mixed-contract government subsidy. This paper attempts to answer the following questions.

(1) How does the difference between decentralized supply chain structure and centralized supply chain structure affect the decision-making of CSR in the supply chain?

(2) What is the impact of delay effect on the optimal decision of CSR in the supply chain?

(3) What is the impact of government subsidy rate on the optimal decision-making of CSR in the supply chain?

(4) In different scenarios, how to improve the performance level of supply chain CSR?

The arrangement of this paper is as follows. In Section 2, the variables and functions of the basic model are described. In Section 3, we use the differential game model to discuss the CSR decision-making of supply chain enterprises in five scenarios. Numerical simulation and analysis are shown in Section 4. The research conclusions and further improvement direction are described in Section 5 .

\section{Basic Model}

This paper is based on a two-echelon supply chain composed of upstream manufacturers and downstream retailers, assuming that all participants are completely rational and chasing profit maximization. In the wake of more consumers with CSR preferences, the state's concern, and governance of CSR, supply chain enterprises are encouraged to actively undertake CSR. For example, the existence of CSR can be observed in the supply chain composed of well-known manufacturers (e.g., Nike, P\&G) and retailers (e.g., Walmart, Kroger) [29]. In this regard, manufacturers actively invest in CSR activities, research and develop, and produce the products with CSR attributes. In order to improve the reputation of enterprises, retailers need to increase advertising investment to educate customers about social responsibility of products and to improve market demands. In addition, the government will provide cost subsidies to manufacturers and retailers to encourage CSR-related investment. In order to explore the cooperative strategy of CSR collaborative governance in supply chains from a dynamic perspective, this paper mainly discusses the following situations. (1) Manufacturers and retailers make CSR decisions with the optimal concentration of total profits in the supply chain. (2) Manufacturers and retailers make CSR decisions with the optimal dispersion of respective profits. (3) Manufacturers and retailers cooperate through mixed contracts to make CSR decisions with the best distribution of their profits. (4) With government subsidies, the manufacturer and the retailer make the CSR decision with the best profit dispersion. (5) With government subsidies, the manufacturer and the retailer cooperate with each other through the mixed contract and make the CSR decision with the best profit dispersion. The supply chain structure and decision-making models studied in this paper are shown in Figure 1. 


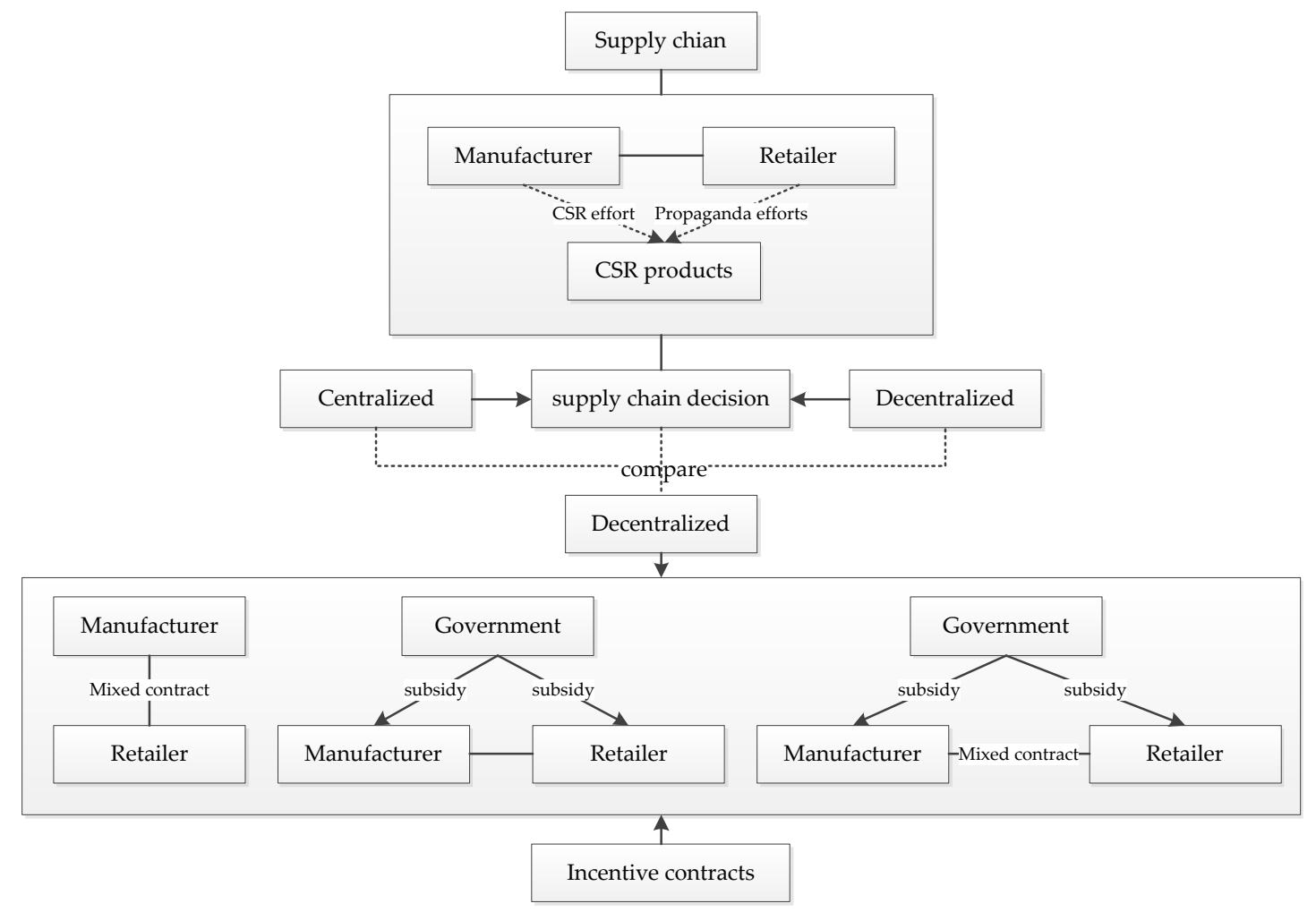

Figure 1. Supply chain structures and decision-making models.

Combined with the previous literature research results, this paper puts forward the following assumptions.

(1) In order to fulfill CSR, enterprises must bear certain investment costs. Manufacturers improve the green degree and safety level of products mostly through green raw material procurement, technical innovations and production line supervision, etc. Retailers publicize CSR products mainly through marketing methods. Assuming that the wholesale price of the product determined by the manufacturer at $t$ time is $w(t)$. CSR effort is denoted by $y_{m}(t)$. The retail price determined by the retailer at $t$ time is $p(t)$. Advertising effort is denoted by $y_{r}(t)$.

(2) Assuming that the fixed cost of the manufacturer's CSR products is $c$. The manufacturer's CSR performance cost and the retailer's advertising cost are convex functions of their efforts, which are generally expressed as quadratic cost functions [30]. That is to say, the cost of fulfilling the manufacturer's CSR at $t$ time is $C_{m}=\frac{\eta_{m} y_{m}^{2}(t)}{2}$, the advertising cost of retailers is $C_{r}=\frac{\eta_{r} y_{r}^{2}(t)}{2}$, where $\eta_{m}>0$ and $\eta_{r}>0$ are the cost coefficients of manufacturer's CSR performance and retailer's advertising respectively.

(3) The performance of CSR can increase intangible assets such as brand value or reputation value to improve the enterprise's market competitiveness, while the performance effect of CSR often has a delayed impact. Based on the Nerlove-Arrow model, this paper uses the delayed differential equation to describe dynamic changes of the performance level of CSR of unit product [31].

$$
\dot{T}(t)=\gamma y_{m}(t-d)-\delta T(t)
$$

where $T(t)$ represents the level of CSR of unit product at time $t$, and the initial level of CSR is $T(0)=T_{0}, T_{0} \geq 0 . \gamma$ is the influence coefficient capturing the manufacturer's efforts to take CSR on the unit product's performance level of CSR. $\delta>0$ indicates the decay rate of CSR level of unit product when the manufacturer does not carry out CSR activities. $d$ indicates the time delay of 
market effect caused by the manufacturer's CSR activities. The reason for the delay effect is that the transformation of CSR investment into CSR performance needs a process.

(4) On the one hand, corporate reputation is related to products' level of CSR; on the other hand, it is also related to retailers' level of product promotion. Referring to Herbon's treatment method, the dynamic process of corporate reputation is described by differential equation as follows [32].

$$
\dot{G}(t)=\varphi T(t)+\lambda y_{r}(t)-\vartheta G(t)
$$

where $G(t)$ represents the reputation of the company at $t$ time, initial corporate reputation of products is $G(0)=G_{0}, G_{0} \geq 0 . \varphi>0$ and $\lambda>0$ indicates the influence coefficient capturing CSR level and a retailer's advertising efforts on corporate reputation, respectively. $\vartheta>0$ is the decay rate of corporate reputation.

(5) The demand of CSR products is influenced by nonprice factors such as the level of CSR, retailers' advertising efforts, and consumers' preference for social responsibility. Advertising efforts invested by retailers directly drive demands, while the level of CSR of unit product is improved by manufacturers through CSR investment, which would have a further impact on product demands. Secondly, the demand is also influenced by price factors. Consumers tend to buy products with a higher level of CSR and lower prices. The lower the price, the greater the market demand. As learnt from the Ouardighi model, two aspects are designed separately to influence the product demand simultaneously through multiplication [33].

$$
D(t)=(a-b p(t)) k G(t)
$$

where $a>0$ is potential market demand, and $b>0$ is the price sensitivity coefficient, indicating retail price's impacts on product demand. To ensure that the product demand is not negative, set $a-b p(t)>0 . k>0$ is consumers' preference coefficient of social responsibility.

(6) This assuming that both manufacturers and retailers make rational decisions based on exhaustive information, excluding supply chain inventory cost and out-of-stock cost. In an infinite time range, manufacturers and retailers have the same discount rate, $\rho>0$, at any certain time point. Both parties take a decision criteria, which is to pursue their own profit maximization. To sum up, the objective functions of the manufacturer, the retailer, and the entire supply chain are as follows.

$$
\begin{gathered}
J_{m}=\max _{w(t), y_{m}(t)} \int_{0}^{\infty} e^{-\rho t}\left[(w(t)-c) \cdot D(t)-C_{m}\right] d t \\
J_{r}=\max _{p(t), y_{r}(t)} \int_{0}^{\infty} e^{-\rho t}\left[(p(t)-w(t)) \cdot D(t)-C_{r}\right] d t \\
J_{s c}=\max _{p(t), y_{m}(t), y_{r}(t)} \int_{0}^{\infty} e^{-\rho t}\left[(p(t)-c) \cdot D(t)-C_{m}-C_{r}\right] d t
\end{gathered}
$$

\section{Model Formulation}

\subsection{Basic Model of Supply Chain Corporate Social Responsibility}

\subsubsection{Centralized Supply Chain Decision}

In a centralized decision-making process, manufacturers and retailers build a stable cooperation mechanism together to make decisions pursuing the supply chain's overall profit maximization (the superscript $c$ below indicates a centralized decision-making situation). According to the optimal control theory, this paper used the Hamilton-Jacobi-Bellman (HJB) equation to solve this problem.

Proposition 1. The following results can be obtained by solving the centralized decision model. 
(1) The optimal game strategies of manufacturers and retailers are $p^{c *}, y_{m}^{c *}, y_{r}{ }^{c *} \cdot p^{c *}=\frac{a+b c}{2 b}$, $y_{m}^{c *}=\frac{\gamma \varphi k(a-b c)^{2} e^{\delta d}}{4 b \eta_{m}(\rho+\delta)(\rho+\vartheta)}, y_{r}^{c *}=\frac{(a-b c)^{2} \cdot \lambda k}{4 b \eta_{r}(\rho+\vartheta)}$.

(2) The optimal path of supply chain enterprises' social responsibility level is $T^{* *}$. $T(t)^{c *}=e^{-\delta t} T_{0}+A_{1} \cdot\left(1-e^{-\delta t}\right)$, where $A_{1}=\frac{\gamma^{2} \varphi k(a-b c)^{2} e^{\delta d}}{4 \delta b \eta_{m}(\rho+\delta)(\rho+\vartheta)}$.

(3) The optimal path of supply chain enterprises' reputation is $G^{c *} \cdot G(t)^{c *}=e^{-\vartheta t}$. $\left[G_{0}-\frac{\varphi\left(T_{0}-A_{1}\right)}{\vartheta-\delta}-\frac{\varphi A_{1}+B_{1}}{\vartheta}\right]+\frac{\varphi\left(T_{0}-A_{1}\right)}{\vartheta-\delta} \cdot e^{-\delta t}+\frac{\varphi A_{1}+B_{1}}{\vartheta}$, where $B_{1}=\frac{(a-b c)^{2} \cdot \lambda^{2} k}{4 b \eta_{r}(\rho+\vartheta)}$.

(4) The overall profit of the supply chain is $J_{s c}^{c *}(T, G) . J_{s c}^{c *}(T, G)=e^{-\rho t}\left(l_{1}^{*} T+m_{1}^{*} G+n_{1}^{*}\right)$, where $l_{1}^{*}=\frac{(a-b c)^{2} \cdot \varphi k}{4 b(\rho+\delta)(\rho+\vartheta)}, m_{1}^{*}=\frac{(a-b c)^{2} \cdot k}{4 b(\rho+\vartheta)}, n_{1}^{*}=\frac{(a-b c)^{4} k^{2}}{32 b^{2} \rho(\rho+\vartheta)^{2}}\left[\frac{\lambda^{2}}{\eta_{r}}+\frac{\varphi^{2} \gamma^{2}\left(2 e^{\delta d}-e^{2 \delta d}\right)}{\eta_{m}(\rho+\delta)^{2}}\right]$.

Proof. According to Equation (6), the overall optimal profit function of the supply chain at $t$ time is

$$
\begin{aligned}
& J_{s c}^{c *}=\max _{p, y_{m}, y_{r}} \int_{t}^{\infty} e^{-\rho s}\left[(p-c)(a-b p) k G-\frac{1}{2} \eta_{m} y_{m}^{2}-\frac{1}{2} \eta_{r} y_{r}^{2}\right] d s \\
= & e^{-\rho t} \max _{p, y_{m}, y_{r}} \int_{t}^{\infty} e^{-\rho(s-t)}\left[(p-c)(a-b p) k G-\frac{1}{2} \eta_{m} y_{m}^{2}-\frac{1}{2} \eta_{r} y_{r}^{2}\right] d s
\end{aligned}
$$

Let $V_{s c}^{c}(T, G)=\max _{p, y_{m}, y_{r}} \int_{t}^{\infty} e^{-\rho(s-t)}\left[(p-c)(a-b p) k G-\frac{1}{2} \eta_{m} y_{m}^{2}-\frac{1}{2} \eta_{r} y_{r}^{2}\right] d s$, according to the optimal control theory; the following HJB equation can be obtained.

$$
\rho V_{s c}^{c}(T, G)=\max _{p, y_{m}, y_{r}}\left[\begin{array}{l}
(p-c)(a-b p) k G-\frac{1}{2} \eta_{m} y_{m}^{2}-\frac{1}{2} \eta_{r} y_{r}^{2}+\frac{\partial V_{s c}^{c}}{\partial T}\left(\gamma y_{m}(t-d)-\delta T\right) \\
+\frac{\partial V_{s c}^{c}}{\partial G}\left(\varphi T(t)+\lambda y_{r}(t)-\vartheta G(t)\right)
\end{array}\right]
$$

The first partial derivatives of $p, y_{m}$ and $y_{r}$ are calculated for the right end of Equation (8), and let them be equal to 0 . Let $\frac{\partial y_{m}(t-d)}{\partial y_{m}}=e^{\delta d}$ (based on the research of Basin), Equation (9) can be obtained [34].

$$
p=\frac{a+b c}{2 b}, y_{m}=\frac{\partial V_{s c}^{c}}{\partial T} \frac{\gamma e^{\delta d}}{\eta_{m}}, y_{r}=\frac{\lambda}{\eta_{r}} \frac{\partial V_{s c}^{c}}{\partial G}
$$

Substituting Equation (9) into Equation (8) and sorting out Equation (10):

$$
\begin{gathered}
\rho V_{s c}^{c}(T, G)=\frac{(a-b c)^{2}}{4 b} \cdot k G-\frac{1}{2} \cdot \frac{\gamma^{2} e^{2 \delta d}}{\eta_{m}} \cdot \frac{\partial^{2} V}{\partial^{2} T}-\frac{1}{2} \cdot \frac{\lambda^{2}}{\eta_{r}} \cdot \frac{\partial^{2} V}{\partial^{2} G} \\
\quad+\frac{\partial V}{\partial T}\left[\gamma y_{m}(t-d)-\delta T\right]+\frac{\partial V}{\partial G}\left(\varphi T+\frac{\lambda^{2}}{\eta_{r}} \cdot \frac{\partial V}{\partial G}-\vartheta G\right)
\end{gathered}
$$

By observing the characteristics of the differential equation, we can assume that the linear analytic expression of function $V_{s c}^{c}$ about $T$ and $G$ is $V_{s c}^{c}(T, G)=l_{1} T+m_{1} G+n_{1}$, where $l_{1}, m_{1}, n_{1}$ are constants. Obviously, $\frac{\partial V}{\partial T}=l_{1}, \frac{\partial V}{\partial G}=m_{1}$. By substituting $V_{s c}^{c}, \frac{\partial V}{\partial T}$ and $\frac{\partial V}{\partial G}$ into Equation (10), and then comparing the coefficients of the same terms at both ends of the equation, we can get $l_{1}{ }^{*}, m_{1}{ }^{*}, n_{1}^{*}$.

$$
\begin{gathered}
l_{1}^{*}=\frac{(a-b c)^{2} \cdot \varphi k}{4 b(\rho+\delta)(\rho+\vartheta)}, m_{1}^{*}=\frac{(a-b c)^{2} \cdot k}{4 b(\rho+\vartheta)}, \\
n_{1}^{*}=\frac{(a-b c)^{4} k^{2}}{32 b^{2} \rho(\rho+\vartheta)^{2}}\left[\frac{\lambda^{2}}{\eta_{r}}+\frac{\varphi^{2} \gamma^{2}\left(2 e^{\rho d}-e^{2 \delta d}\right)}{\eta_{m}(\rho+\delta)^{2}}\right]
\end{gathered}
$$

The optimal solution of supply chain system can be obtained by substituting $V_{s c}^{c}, l_{1}{ }^{*}$ and $m_{1}{ }^{*}$ into Equation (9).

$$
p^{c *}=\frac{a+b c}{2 b}, y_{m}^{c *}=\frac{\gamma \varphi k(a-b c)^{2} e^{\delta d}}{4 b \eta_{m}(\rho+\delta)(\rho+\vartheta)}, y_{r}^{c *}=\frac{(a-b c)^{2} \cdot \lambda k}{4 b \eta_{r}(\rho+\vartheta)}
$$

By substituting Equation (12) into Equation (1), and according to boundary condition of state equation, $T(0)=T_{0}$, the optimal trajectory expression of CSR level of supply chain, can be obtained as shown in Proposition 1 (2). By substituting Equation (12) into Equation (2), and according to boundary 
condition of state equation, $G(0)=G_{0}$, the optimal trajectory expression of supply chain reputation can be obtained as shown in Proposition 1 (3). Finally, by substituting Equation (12) into Equation (7), we can get the optimal value function of the overall profit of the supply chain, as shown in Proposition 1 (4).

\subsubsection{Decentralized Supply Chain Decision}

In this case, both manufacturers and retailers make independent decisions based on the maximization of their own interests respectively. Manufacturers determine the level of CSR efforts $y_{m}$ and wholesale price of products $w$. Retailers determine the level of advertising efforts $y_{r}$ and retail price $p$ based on manufacturers' decisions. This problem can be solved by the reverse induction method (the superscript $d$ below indicates decentralized decision-making).

Proposition 2. The following results can be obtained by solving the decentralized supply chain decision-making model.

(1) The optimal game strategies of manufacturers and retailers are $\left(w^{d *}, y_{m}^{d *}\right),\left(p^{d *}, y_{r}^{d *}\right) \cdot w^{d *}=$ $\frac{a+b c}{2 b}, y_{m}^{d *}=\frac{k \varphi \gamma(a-b c)^{2} e^{\delta d}}{8 b \eta_{m}(\rho+\vartheta)(\rho+\delta)}, p^{d *}=\frac{3 a+b c}{4 b}, y_{r}^{d *}=\frac{(a-b c)^{2} \lambda k}{16 b \eta_{r}(\rho+\vartheta)}$.

(2) The optimal path of supply chain enterprises' social responsibility level is $T^{d *} \cdot T(t)^{d *}=e^{-\delta t} T_{0}+A_{2}\left(1-e^{-\delta t}\right)$, where $A_{2}=\frac{k \varphi \gamma^{2}(a-b c)^{2} e^{\delta d}}{8 \delta b \eta_{m}(\rho+\vartheta)(\rho+\delta)}$.

(3) The optimal path of supply chain enterprises' reputation is $G^{d *} \cdot G(t)^{d *}=e^{-\vartheta t}$. $\left[G_{0}-\frac{\varphi\left(T_{0}-A_{2}\right)}{\vartheta-\delta}-\frac{\varphi A_{2}+B_{2}}{\vartheta}\right]+\frac{\varphi\left(T_{0}-A_{2}\right)}{\vartheta-\delta} \cdot e^{-\delta t}+\frac{\varphi A_{2}+B_{2}}{\vartheta}$, where $B_{2}=\frac{(a-b c)^{2} \lambda^{2} k}{16 b \eta_{r}(\rho+\vartheta)}$.

(4) The optimal profit functions of manufacturers and retailers are $J_{m}^{d *}(T, G), J_{r}^{d *}(T, G) \cdot J_{m}^{d *}(T, G)=$ $e^{-\rho t}\left(s_{1}^{*} T+s_{2}^{*} G+s_{3}^{*}\right)$, where $l_{2}^{*}=\frac{k \varphi(a-b c)^{2}}{8 b(\rho+\vartheta)(\rho+\delta)}, m_{2}^{*}=\frac{k(a-b c)^{2}}{8 b(\rho+\vartheta)}, n_{2}^{*}=\frac{(a-b c)^{4} k^{2}}{64 b^{2} \rho(\rho+\vartheta)^{2}}\left[\frac{\lambda^{2}}{\eta_{r}}+\frac{\varphi^{2} \gamma^{2}\left(2 e^{\delta d}-e^{2 \delta d}\right)}{2 \eta_{m}(\rho+\delta)^{2}}\right]$.

$J_{r}^{d *}(T, G)=e^{-\rho t}\left(m_{1}^{*} T+m_{2}^{*} G+m_{3}^{*}\right), \quad$ where $l_{3}^{*}=\frac{(a-b c)^{2} k}{16 b(\rho+\vartheta)(\rho+\delta)}, \quad m_{3}^{*}=\frac{(a-b c)^{2} k}{16 b(\rho+\vartheta)}$, $n_{3}^{*}=\frac{(a-b c)^{4} k^{2}}{256 b^{2} \rho(\rho+\vartheta)^{2}}\left[\frac{\lambda^{2}}{2 \eta_{r}}+\frac{\varphi^{2} \gamma^{2} e^{\delta d}}{(\rho+\delta)^{2} \eta_{m}}\right]$.

Proof. From Equation (5), it can be seen that the optimal profit function of the retailer at $t$ time is Equation (13).

$$
\begin{aligned}
& J_{r}^{d *}=\max _{p(t), y_{r}(t)} \int_{t}^{\infty} e^{-\rho s}\left[(p(t)-\omega)(a-b p(t)) k G(t)-\frac{1}{2} \eta_{r} y_{r}^{2}(t)\right] d s \\
= & e^{-\rho t} \max _{p(t), y_{r}(t)} \int_{t}^{\infty} e^{-\rho(s-t)}\left[(p(t)-\omega)(a-b p(t)) k G(t)-\frac{1}{2} \eta_{r} y_{r}^{2}(t)\right] d s
\end{aligned}
$$

Let $V_{r}^{d}(T, G)=\max _{p(t), y_{r}(t)} \int_{t}^{\infty} e^{-\rho(s-t)}\left[(p(t)-\omega)(a-b p(t)) k G(t)-\frac{1}{2} \eta_{r} y_{r}^{2}(t)\right] d s$, then the retailer's optimal profit function at $t$ time can be expressed as Equation (14).

$$
J_{r}^{d *}=e^{-\rho t} V_{r}^{d}(T, G)
$$

According to the optimal control theory, the following HJB equation can be obtained.

$$
\rho V_{r}^{d}(T, G)=\max _{p, y_{r}}\left[\begin{array}{l}
(p-w)(a-b p) k G-\frac{1}{2} \eta_{r} y_{r}^{2}+\frac{\partial V_{r}^{d}}{\partial T}\left(\gamma y_{m}(t-d)-\delta T\right) \\
+\frac{\partial V_{r}^{d}}{\partial G}\left(\varphi T+\lambda y_{r}-\vartheta G\right)
\end{array}\right]
$$

The first partial derivatives of $p$ and $y_{r}$ are calculated for the right end of Equation (15), and let them be equal to 0 , then we can get Equation (16).

$$
p^{d *}=\frac{a+b w}{2 b}, y_{r}=\frac{\lambda}{\eta_{r}} \frac{\partial V_{r}^{d}}{\partial G}
$$


Similarly, the optimal profit function of the manufacturer at time $t$ is $J_{m}^{d *}=e^{-\rho t} V_{m}^{d}(T, G)$. According to the optimal control theory, the following HJB equation can be obtained.

$$
\rho V_{m}^{d}(T, G)=\max _{w, y_{m}}\left[\begin{array}{l}
(w-c)(a-b p) k G-\frac{1}{2} \eta_{m} y_{m}^{2}+\frac{\partial V_{m}^{d}}{\partial T}\left(\gamma y_{m}(t-d)-\delta T\right) \\
+\frac{\partial V_{m}^{d}}{\partial G}\left(\varphi T+\lambda y_{r}-\vartheta G\right)
\end{array}\right]
$$

Substituting Equation (16) into Equation (17) and making the first partial derivative of $w$ and $y_{m}$ on the right end of Equation (17) equal to 0, we can get Equation (18).

$$
w^{d *}=\frac{a+b c}{2 b}, y_{m}=\frac{\partial V_{m}^{d}}{\partial T} \frac{\gamma e^{\delta d}}{\eta_{m}}
$$

Two differential equations can be obtained by substituting Equation (16) and Equation (18) into Equation (15) and Equation (17), respectively. By observing the characteristics of the differential equation, the specific expressions of functions $V_{r}^{d}(T, G)$ and $V_{m}^{d}(T, G)$ are respectively set as follows.

$$
V_{r}^{d}(T, G)=l_{3} T+m_{3} G+n_{3}, V_{m}^{d}(T, G)=l_{2} T+m_{2} G+n_{2}
$$

By substituting Equation (19) into the sorted differential equation, the solution of the equation group can be obtained as follows.

$$
\begin{gathered}
l_{3}^{*}=\frac{(a-b c)^{2} k \varphi}{16 b(\rho+\vartheta)(\rho+\delta)}, m_{3}^{*}=\frac{(a-b c)^{2} k}{16 b(\rho+\vartheta)}, \\
n_{3}^{*}=\frac{(a-b c)^{4} k^{2}}{256 b^{2} \rho(\rho+\vartheta)^{2}}\left[\frac{\lambda^{2}}{2 \eta_{r}}+\frac{\varphi^{2} \gamma^{2} e^{\delta d}}{(\rho+\delta)^{2} \eta_{m}}\right] \\
l_{2}^{*}=\frac{k \varphi(a-b c)^{2}}{8 b(\rho+\vartheta)(\rho+\delta)}, m_{2}^{*}=\frac{k(a-b c)^{2}}{8 b(\rho+\vartheta)}, \\
n_{2}^{*}=\frac{(a-b c)^{4} k^{2}}{64 b^{2} \rho(\rho+\vartheta)^{2}}\left[\frac{\lambda^{2}}{\eta_{r}}+\frac{\varphi^{2} \gamma^{2}\left(2 e^{\rho d d}-e^{2 \delta d}\right)}{2 \eta_{m}(\rho+\delta)^{2}}\right]
\end{gathered}
$$

Substituting $p^{d *}, w^{d *}, m_{3}^{*}$, and $l_{2}^{*}$ into Equation (16) and Equation (18) respectively, the following equations can be obtained.

$$
y_{m}^{d *}=\frac{k \varphi \gamma(a-b c)^{2} e^{\delta d}}{8 b \eta_{m}(\rho+\vartheta)(\rho+\delta)}, y_{r}^{d *}=\frac{(a-b c)^{2} \lambda k}{16 b \eta_{r}(\rho+\vartheta)}
$$

Substituting Equation (22) into Equation (1), and according to the boundary conditions of the state equation $T(0)=T_{0}$, the optimal trajectory expression of the level of CSR of supply chain can be obtained as shown in Proposition 2 (2). Substituting $T^{d *}$ and Equation (22) into Equation (2), and according to the boundary conditions of the state equation $G(0)=G_{0}$, the optimal trajectory expression of supply chain reputation can be obtained as shown in Proposition 2 (3); substituting Equation (22) into Equation (15) and Equation (17) to obtain the optimal profit functions of manufacturer and retailer, respectively, as shown in Proposition 2 (4).

Corollary 1. With increasing preference of consumers for social responsibility, manufacturers and retailers will continue to increase the level of CSR and publicity of social responsibility under centralized and decentralized decision-making modes. As the discount rate rises, manufacturers and retailers will reduce their social responsibility efforts. In addition, with the extension of the time delay, manufacturers will continue to increase the level of social responsibility efforts.

Corollary 2. Under centralized and decentralized decision-making modes, the level of CSR and goodwill in supply chain gradually rise as time goes on. When the time range tends to infinity, both the level of CSR and goodwill in the supply chain approach stable values that are related to the delay time. 
Corollary 3. From $p^{d *}-p^{c *}=\frac{a-b c}{4 b}>0, y_{m}^{d *}-y_{m}^{c *}<0, y_{r}^{d *}-y_{r}^{c *}<0, V_{s c}^{c *}>V_{s c}^{d *}=V_{m}^{d *}+V_{r}^{d *}, \frac{\partial V_{m}^{d *}}{\partial d}<0$, $\frac{\partial V_{r}^{d *}}{\partial d}>0$, compared with centralized decision-making mode, the retail price of social responsibility products is higher under decentralized decision-making mode. Although the overall profit of supply chain is higher under centralized decision-making mode, the manufacturer's social responsibility efforts and the retailer's advertising level are also higher than those under decentralized decision-making mode. With the extension of delay time, profits of manufacturers will continue to decline, while profits of retailers will continue to increase, meaning that the lag effect is not good for manufacturers, but good for retailers.

Corollary 4. There is a threshold for delay time. When $d \geq$ $\left[\ln \left(5+\sqrt{\left[25 \eta_{r} \varphi^{2} \gamma^{2}+33 \lambda^{2} \eta_{m}(\rho+\delta)^{2}\right] / \eta_{r} \varphi^{2} \gamma^{2}}\right)-\ln 6\right] / \delta$, the overall profit of supply chain under decentralized decision-making mode is no lower than that under centralized decision-making mode. Therefore, only when the delay time is shorter than the threshold value, can the centralized decisions made by the cooperation of supply chain members be meaningful. When the delay time is longer than the threshold value, even if the supply chain can achieve a higher level of CSR and advertising efforts under the centralized decision-making mode, rational supply chain members will not choose the centralized decision-making approach, yet tend to choose the decentralized decision-making approach with more luxurious profits, even though it compromises the level of social responsibility and advertising efforts.

\subsection{Decentralized Supply Chain Decision under Incentive Contract}

\subsubsection{Supply Chain Internal Cooperation Incentive}

The above corollaries reveal that the centralized decision-making supply chain can not only encourage manufacturers and retailers to make more CSR efforts, but also lead to higher supply chain profits, which makes an ideal way of cooperation. However, the members of the supply chain in reality are often independent and isolating, pursuing the maximization of their own interests, which makes the centralized decision-making approach difficult to achieve. In order to coordinate the supply chain perfectly, it is necessary to make the game equilibrium strategy of decentralized supply chain and centralized supply chain equal. Under the condition of contract, the present value of profit of each supply chain member is greater than that of decentralized decision-making. Therefore, it is necessary for a basic decentralized decision-making supply chain to establish a mixed contract to achieve the results of a centralized decision-making supply chain. In order to improve the level of CSR, advertising efforts, and their respective earnings, this paper sets up the following ways of contract (using the superscript $S$ to represent the decentralized decision-making situation under the contract).

(1) In order to encourage retailers to publicize CSR products, manufacturers will cooperate with retailers in advertising and share part of the advertising cost of retailers. The share ratio is $\mu(0 \leq \mu \leq 1)$.

(2) In order to achieve a higher level of CSR, manufacturers need to bear higher costs of social responsibility. Retailers shall reduce the cost pressure of manufacturers through cost-sharing contracts. The cost-sharing ratio is $\phi(0 \leq \phi \leq 1)$.

(3) Supply chain coordination can be achieved through considering a revenue-sharing contract to make up for the loss of supply chain efficiency under decentralized decision-making. Retailers shall share the benefits of CSR products with manufacturers with a benefit-sharing coefficient $\theta(0<\theta<1)$. The manufacturer's benefit proportion from selling products is $\theta$, and the retailer's benefit proportion from selling products is $1-\theta$.

Proposition 3. The mixed contract, which is composed of advertising cooperation, cost sharing and revenue sharing, can bring out supply chain coordination. In order to achieve the operation effect of centralized supply chain, the conditions of mixed contract are as follows. 


$$
\begin{gathered}
w=(1-\theta) c, \phi=1-\theta, \mu=\theta, V_{m}^{s} / V_{s c}^{c}<\theta<\left(V_{s c}^{c}-V_{r}^{s}\right) / V_{s c}^{c} \\
d<\left[\ln \left(5+\sqrt{\left[100 \eta_{r} \varphi^{2} \gamma^{2}+87 \lambda^{2} \eta_{m}(\rho+\delta)^{2} / 4 \eta_{r} \varphi^{2} \gamma^{2}\right]}\right)-\ln 6\right] / \delta
\end{gathered}
$$

Proof. The decision-making problems of manufacturers and retailers are as follows.

$$
\begin{aligned}
& J_{m}=\max _{w, y_{m}} \int_{0}^{\infty} e^{-\rho t}\left[(w-c+\theta p)(a-b p) k G-\frac{1}{2}(1-\phi) \eta_{m} y_{m}^{2}-\frac{1}{2} \mu \eta_{r} y_{r}^{2}\right] d t \\
& J_{r}=\max _{p, y_{r}} \int_{0}^{\infty} e^{-\rho t}\left[[(1-\theta) p-\omega](a-b p) k G-\frac{1}{2}(1-\mu) \eta_{r} y_{r}^{2}-\frac{1}{2} \phi \eta_{m} y_{m}^{2}\right] d t
\end{aligned}
$$

From Equation (24), it can be seen that the optimal profit function of the retailer at $t$ time is Equation (25).

$$
J_{r}^{s *}(T, G, t)=e^{-\rho t} V_{r}^{s}(T, G)
$$

where $V_{r}^{s}(T, G)=\max _{p, y_{r}} \int_{t}^{\infty} e^{-\rho(s-t)}\left[[(1-\theta) p-\omega](a-b p) k G-\frac{1}{2}(1-\mu) \eta_{r} y_{r}^{2}-\frac{1}{2} \phi \eta_{m} y_{m}^{2}\right] d s$.

Establish the following HJB equation.

$$
\rho V_{r}^{s}=\max _{p, y_{r}}\left\{\begin{array}{c}
{[(1-\theta) p-\omega](a-b p) k G-\frac{1}{2}(1-\mu) \eta_{r} y_{r}^{2}-\frac{1}{2} \phi \eta_{m} y_{m}^{2}} \\
+\frac{\partial V_{r}^{s}}{\partial T}\left(\gamma y_{m}(t-d)-\delta T\right)+\frac{\partial V_{r}^{s}}{\partial G}\left(\varphi T+\lambda y_{r}-\vartheta G\right)
\end{array}\right\}
$$

For the right end of Equation (26), the first partial derivatives of $p$ and $y_{r}$ are calculated respectively and made equal to 0, we can obtain Equation (27).

$$
p^{s}=\frac{(1-\theta) a+b w}{2 b(1-\theta)}, y_{r}^{s}=\frac{\lambda \frac{\partial V_{r}^{s}}{\partial G}}{(1-\mu) \eta_{r}}
$$

In order to make the optimal profit of the supply chain system under the condition of mixed contract to reach the maximum value under the centralized decision, let $p^{s}=p^{c}$, then we can get Equation (28).

$$
w=(1-\theta) c
$$

From Equation (23), it can be seen that the optimal profit function of the manufacturer at $t$ time is $J_{m}^{s *}(T, G, t)=e^{-\rho t} V_{m}^{s}(T, G)$. According to the optimal control theory, the following HJB equation can be obtained.

$$
\rho V_{m}^{s}(T, G)=\max _{w, y_{m}}\left[\begin{array}{c}
(w-c+\theta p)(a-b p) k G-\frac{1}{2}(1-\phi) \eta_{m} y_{m}^{2}-\frac{1}{2} \mu \eta_{r} y_{r}^{2} \\
+\frac{\partial V_{m}^{s}}{\partial T}\left(\gamma y_{m}(t-d)-\delta T\right)+\frac{\partial V_{m}^{s}}{\partial G}\left(\varphi T+\lambda y_{r}-\vartheta G\right)
\end{array}\right]
$$

Substituting Equation (27) and Equation (28) into Equation (29), and finding the first partial derivative of Formula (29) with respect to $y_{m}$ at the right end, making it equal to 0, we can get Equation (30).

$$
y_{m}^{s}=\frac{\partial V_{m}^{s}}{\partial T} \cdot \frac{\gamma e^{\delta d}}{\eta_{m}(1-\phi)}
$$

By substituting Equations (27), (28), and (30) into Equations (26) and (29), two differential equations can be obtained. According to the characteristics of differential equations, the expressions of functions $V_{r}^{s}(T, G)$ and $V_{m}^{s}(T, G)$ are respectively set as follows.

$$
V_{r}^{s}(T, G)=l_{5} T+m_{5} G+n_{5}, V_{m}^{s}(T, G)=l_{4} T+m_{4} G+n_{4}
$$


$l_{4}, m_{4}, n_{4}, l_{5}, m_{5}$ and $n_{5}$ are undetermined constants. Substituting Equation (31) into two differential equations respectively, we can get the constraint equations about each constant. Solving the equations, we can get as follows.

$$
\begin{gathered}
l_{5}^{s *}=\frac{(a-b c)^{2}(1-\theta) k \varphi}{4 b(\rho+\vartheta)(\rho+\delta)}, m_{5}^{s *}=\frac{(a-b c)^{2}(1-\theta) k}{4 b(\rho+\vartheta)}, \\
n_{5}^{s *}=\frac{(a-b c)^{4}(1-\theta)^{2} k^{2}}{32 \rho b^{2}(\rho+\vartheta)^{2}}\left[\frac{\lambda^{2}}{(1-\mu) \eta_{r}}+\frac{\gamma^{2} \varphi^{2}\left[2(1-\phi) e^{\delta d}-\phi e^{2 \delta d}\right]}{\eta_{m}(1-\phi)^{2}(\rho+\delta)^{2}}\right], \\
l_{4}^{s *}=\frac{(a-b c)^{2} k \varphi \theta}{4 b(\rho+\vartheta)(\rho+\delta)}, m_{4}^{s *}=\frac{(a-b c)^{2} k \theta}{4 b(\rho+\vartheta)} \\
n_{4}^{s *}=\frac{(a-b c)^{4} k^{2} \theta^{2}}{32 \rho b^{2}(\rho+\vartheta)^{2}}\left[\frac{\lambda^{2}(2-3 \mu)}{(1-\mu)^{2} \eta_{r}}+\frac{\gamma^{2} \varphi^{2}\left(2 e^{\delta d}-e^{2 \delta d}\right)}{\eta_{m}(1-\phi)(\rho+\delta)^{2}}\right]
\end{gathered}
$$

Substituting the above results into Equation (27) and Equation (30), we can get Equation (33).

$$
y_{m}^{s *}=\frac{k \varphi \theta \gamma(a-b c)^{2} e^{\delta d}}{4 b \eta_{m}(\rho+\vartheta)(\rho+\delta)(1-\phi)}, y_{r}^{s *}=\frac{k \lambda(a-b c)^{2}(1-\theta)}{4 b \eta_{r}(\rho+\vartheta)(1-\mu)}
$$

Let $y_{m}^{s *}=y_{m}^{c *}, y_{r}^{s *}=y_{r}^{c *}$, then $\phi=1-\theta, \mu=\theta$. We can know $V_{m}^{s *}=\theta V_{s c}^{c *}, V_{r}^{s *}=(1-\theta) V_{s c}^{c *}$.

In order for manufacturers and retailers to accept the contract, it is necessary to ensure that the present value of profits of manufacturers and retailers under the contract is greater than the present value of profits under the decentralized decision-making. That is $\theta V_{s c}^{c *}>V_{m}^{s *}$ and $(1-\theta) V_{s c}^{c *}>V_{r}^{s *}$. In addition, to ensure the existence of $\theta$, there must be $V_{s c}^{c *}>V_{r}^{d *}+V_{m}^{d *}$, which means that the delay time must be within the threshold value of Corollary 4 .

\subsubsection{Supply Chain External Cooperation Incentive}

To encourage supply chain members to invest more CSR costs, the government provides manufacturers and retailers with CSR cost subsidies. Suppose that the government subsidy is mainly based on the CSR efforts of manufacturers and retailers. Let $S$ represent the number of government subsidies, and $s(0 \leq s \leq 1)$ is the government subsidy coefficient, then $S=s \cdot C\left(E_{i}(t)\right)(i=m, r)$ (the superscript $g$ below indicates decentralized decision-making under government subsidies).

Proposition 4. To solve the decentralized supply chain decision-making model under government subsidies, we can get as follows.

(1) The profit of manufacturers and retailers, the performance level of CSR and the level of advertising are positively correlated with the subsidy rate of the government.

(2) In order to achieve the operation effect of centralized supply chain decision-making, the optimal subsidy rates of the government to manufacturers and retailers are $1 \geq s_{m} \geq \frac{1}{2}, 1 \geq s_{r} \geq \frac{3}{4}$.

Proof. The solving process regarding the optimal game strategy of manufacturer and retailer, the optimal trajectory of the level of CSR in supply chain, the corporate reputation, and the optimal profit of manufacturer and retailer are similar to the proof process of Proposition 2, this paper will not repeat it here.

To find the first partial derivative of $y_{m}^{g *}$ with respect to $s_{m}$, we can get Equation (34).

$$
\frac{\partial y_{m}^{g^{*}}}{\partial s_{m}}=\frac{(a-b c)^{2} k \varphi \gamma e^{\delta d}}{8 b \eta_{m}(\rho+\vartheta)(\rho+\delta)\left(1-s_{m}\right)^{2}}>0
$$

According to Equation (34), there is a positive correlation between the performance level of CSR of manufacturers and government subsidies. Similarly, $\partial y_{r}^{g *} / \partial s_{r}>0, \partial J_{m}^{g *} / \partial s_{m}>0, \partial J_{r}^{g *} / \partial s_{r}>0$, $\partial J_{m}^{g *} / \partial s_{r}>0, \partial J_{r}^{g *} / \partial s_{m}>0$. That is to say, under the decentralized decision-making, the profit of 
manufacturers and retailers, the performance level of CSR, and the level of advertising are positively correlated with the subsidy rate of the government.

In order to achieve the operation results of the centralized supply chain decision-making approach, let $y_{m}^{g *}=y_{m}^{c *}, y_{r}^{g *}=y_{r}^{c *}$, we can get the value of $s_{m}$ and $s_{r}$.

$$
\begin{aligned}
& y_{m}^{g^{*}}=\frac{(a-b c)^{2} k \varphi \gamma e^{\delta d}}{8 b \eta_{m}(\rho+\vartheta)(\rho+\delta)\left(1-s_{m}\right)}=y_{m}^{c *}=\frac{\gamma \varphi k(a-b c)^{2} e^{\delta d}}{4 b \eta_{m}(\rho+\delta)(\rho+\vartheta)} \\
& y_{r}^{g^{*}}=\frac{(a-b c)^{2} k \lambda}{16 b \eta_{r}(\rho+\vartheta)\left(1-s_{r}\right)}=y_{r}^{c *}=\frac{(a-b c)^{2} \cdot \lambda k}{4 b \eta_{r}(\rho+\vartheta)} \\
& s_{m}=\frac{1}{2}, s_{r}=\frac{3}{4}
\end{aligned}
$$

\subsubsection{Supply Chain Internal and External Cooperation Incentive}

In real life, it is necessary to collaborate the internal and external governance of the supply chain. It means that the supply chain should strengthen the contractual relationship, and the government as an external stakeholder should strengthen the incentive to supply chain members, so as to jointly improve the performance level of CSR.

Proposition 5. In order to achieve the operation results of the centralized supply chain decision-making approach, the conditions to be met under government subsidies and mixed contracts are as follows.

$$
\begin{gathered}
w=(1-\theta) c, \phi=1-\theta-s_{m}, \mu=\theta-s_{r},\left(V_{m}^{d *}+s_{r} V_{s c}^{c *}\right) / V_{s c}^{c *}<\theta<\left(V_{s c}^{c *}-V_{r}^{d *}-s_{m} V_{s c}^{c *}\right) / V_{s c}^{c *}, \\
d<\left[\ln \left(5+\sqrt{\left[100 \eta_{r} \varphi^{2} \gamma^{2}+87 \lambda^{2} \eta_{m}(\rho+\delta)^{2} / 4 \eta_{r} \varphi^{2} \gamma^{2}\right]}\right)-\ln 6\right] / \delta
\end{gathered}
$$

The decision-making problems of manufacturers and retailers are as follows (using superscript $h$ to represent the decentralized supply chain decision-making under internal and external cooperation).

$$
\begin{aligned}
& J_{m}=\max _{w, y_{m}} \int_{0}^{\infty} e^{-\rho t}\left[(w-c+\theta p)(a-b p) k G-\frac{1}{2}\left(1-\phi-s_{m}\right) \eta_{m} y_{m}^{2}-\frac{1}{2} \mu \eta_{r} y_{r}^{2}\right] d t \\
& J_{r}=\max _{p, y_{r}} \int_{0}^{\infty} e^{-\rho t}\left[[(1-\theta) p-\omega](a-b p) k G-\frac{1}{2}\left(1-\mu-s_{r}\right) \eta_{r} y_{r}^{2}-\frac{1}{2} \phi \eta_{m} y_{m}^{2}\right] d t
\end{aligned}
$$

According to Equation (36), the optimal profit function of retailer at $t$ time is Equation (37).

$$
J_{r}^{h *}(T, G, t)=e^{-\rho t} V_{r}^{h}(T, G)
$$

Establish the following HJB equation.

$$
\rho V_{r}^{h}=\max _{p, y_{r}}\left\{\begin{array}{l}
{[(1-\theta) p-\omega](a-b p) k G-\frac{1}{2}\left(1-\mu-s_{r}\right) \eta_{r} y_{r}^{2}-\frac{1}{2} \phi \eta_{m} y_{m}^{2}} \\
+\frac{\partial V_{r}^{h}}{\partial T}\left(\gamma y_{m}(t-d)-\delta T\right)+\frac{\partial V_{r}^{h}}{\partial G}\left(\varphi T+\lambda y_{r}-\vartheta G\right)
\end{array}\right\}
$$

For the right end of Equation (38), the first partial derivatives of $p$ and $y_{r}$ are obtained respectively. Then let they be equal to 0 .

$$
\mathrm{p}=\frac{a(1-\theta)+b w}{2 b(1-\theta)}, y_{r}=\frac{\partial V_{r}^{h}}{\partial G} \frac{\lambda}{\eta_{r}\left(1-\mu-s_{r}\right)}
$$

In the case of internal and external cooperation in the supply chain, in order to make the present value of the supply chain system's optimal profit reach the maximum value under the centralized decision-making approach, let $p^{h}=p^{c}$, then Equation (40) can be obtained.

$$
w=(1-\theta) c
$$


According to Equation (35), the manufacturer's optimal profit function at $t$ time is $J_{m}^{h *}(T, G, t)=e^{-\rho t} V_{m}^{h}(T, G)$. According to the optimal control theory, the following HJB equation can be obtained.

$$
\rho V_{m}^{h}(T, G)=\max _{w, y_{m}}\left[\begin{array}{l}
(w-c+\theta p)(a-b p) k G-\frac{1}{2}\left(1-\phi-s_{m}\right) \eta_{m} y_{m}^{2}-\frac{1}{2} \mu \eta_{r} y_{r}^{2} \\
+\frac{\partial V_{m}^{s}}{\partial T}\left(\gamma y_{m}(t-d)-\delta T\right)+\frac{\partial V_{m}^{s}}{\partial G}\left(\varphi T+\lambda y_{r}-\vartheta G\right)
\end{array}\right]
$$

Substituting Equation (39) and Equation (40) into Equation (41), and finding the first partial derivative of Equation (41) with respect to $y_{m}$ at the right end, making it equal to 0, we can get Equation (42).

$$
y_{m}^{h}=\frac{\partial V_{m}^{h}}{\partial T} \cdot \frac{\gamma e^{\delta d}}{\eta_{m}\left(1-\phi-s_{m}\right)}
$$

By substituting Equations (39), (40), and (42) into Equations (38) and (41), two differential equations can be obtained. According to the characteristics of the differential equations, the expressions of functions $V_{r}^{h}(T, G)$ and $V_{m}^{h}(T, G)$ are respectively set as follows.

$$
V_{r}^{h}(T, G)=l_{9} T+m_{9} G+n_{9}, V_{m}^{h}(T, G)=l_{8} T+m_{8} G+n_{8}
$$

By substituting Equation (43) into two differential equations respectively, the constraint equations of each constant can be obtained.

$$
\begin{gathered}
l_{9}^{h *}=\frac{(1-\theta)(a-b c)^{2} k \varphi}{4 b(\rho+\vartheta)(\rho+\delta)}, m_{9}^{h *}=\frac{(1-\theta)(a-b c)^{2} k}{4 b(\rho+\vartheta)}, \\
n_{9}^{h *}=\frac{(1-\theta)^{2}(a-b c)^{4} k^{2}}{32 b^{2} \rho(\rho+\vartheta)^{2}}\left[\frac{\lambda^{2}}{\eta_{r}\left(1-\mu-s_{r}\right)}+\frac{\gamma^{2} \varphi^{2}\left(2 e^{\delta d}\left(1-\phi-s_{m}\right)-\phi e^{2 \delta d}\right)}{\eta_{m}\left(1-\phi-s_{m}\right)^{2}(\rho+\delta)^{2}}\right], \\
l_{8}^{h *}=\frac{\theta k \varphi(a-b c)^{2}}{4 b(\rho+\vartheta)(\rho+\delta)}, m_{8}^{h *}=\frac{\theta k(a-b c)^{2}}{4 b(\rho+\vartheta)} \\
n_{8}^{h *}=\frac{\theta^{2} k^{2}(a-b c)^{4}}{32 b^{2} \rho(\rho+\vartheta)^{2}}\left[\frac{\lambda^{2}\left(2-3 \mu-2 s_{r}\right)}{\eta_{r}\left(1-\mu-s_{r}\right)^{2}}+\frac{\gamma^{2} \varphi^{2}\left(2 e^{\delta d}-e^{2 \delta d}\right)}{\eta_{m}\left(1-\phi-s_{m}\right)(\rho+\delta)^{2}}\right]
\end{gathered}
$$

Substituting Equation (44) into Equation (39) and Equation (42), we can get Equation (45).

$$
y_{m}^{h *}=\frac{\theta k \varphi \gamma(a-b c)^{2} e^{\delta d}}{4 b \eta_{m}(\rho+\vartheta)(\rho+\delta)\left(1-\phi-s_{m}\right)}, y_{r}^{h *}=\frac{(1-\theta)(a-b c)^{2} k \lambda}{4 b \eta_{r}(\rho+\vartheta)\left(1-\mu-s_{r}\right)}
$$

Let $y_{m}^{h *}=y_{m}^{c *}, y_{r}^{h *}=y_{r}^{c *}$, then $\phi=1-\theta-s_{m}, \mu=\theta-s_{r}$, so we can get $V_{m}^{s *}=\left(\theta-s_{r}\right) V_{s c}^{c *}, V_{r}^{s *}=$ $\left(1-\theta-s_{m}\right) V_{s c}^{c *}$.

In order for manufacturers and retailers to accept the contract, it is necessary to ensure that the present value of profits of manufacturers and retailers under the contract is greater than the present value of profits under the decentralized decision-making. That is $\left(\theta-s_{r}\right) V_{s c}^{c *}>V_{m}^{d *}$ and $\left(1-\theta-s_{m}\right) V_{s c}^{c *}>V_{r}^{d *}$. In addition, to ensure the existence of $\theta$, there must be $V_{s c}^{c *}>V_{r}^{d *}+V_{m}^{d *}$, that is, the delay time must be within the threshold value of Corollary 4 .

\section{Numerical Analysis}

This paper will further verify the above conclusions through numerical simulation, and carry out sensitivity analysis on some important parameters. Referring to the relevant parameter settings in the literature [35], the following parameter values are set as benchmarks. $c=1, \rho=0.3, \delta=0.2, T_{0}=5$, $G_{0}=15, a=5, b=2, \eta_{m}=1, \eta_{r}=1, \gamma=0.8, \varphi=1, \lambda=0.5, \vartheta=0.3, k=0.5$.

(1) When $d=0.2$, the sensitivity analysis of discount rate $\rho$ and consumer social responsibility preference coefficient $k$ to manufacturer's CSR efforts $y_{m}$ and retailer's advertising efforts $y_{r}$ is shown in Figure 2. 

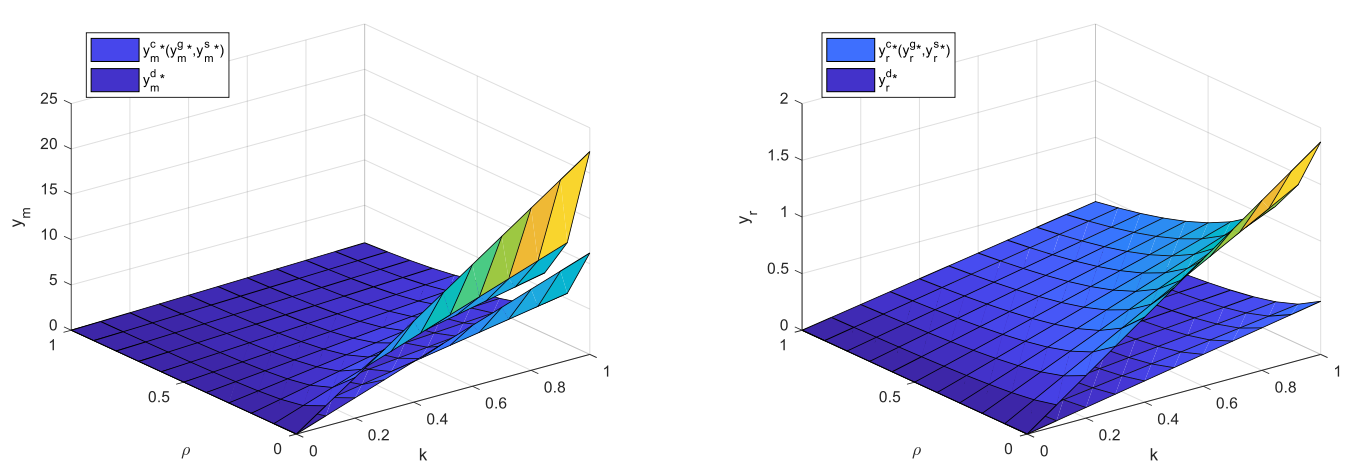

Figure 2. Effect of $\rho$ and $k$ on $y_{m}$ and $y_{r}$.

As can be seen from Figure 1, as discount rate increases, the manufacturer's CSR efforts and the retailer's advertising efforts decline. As consumers' social responsibility preference coefficient increases, the manufacturer's CSR efforts and the retailer's advertising efforts rise, which is consistent with the previous conclusions.

(2) The sensitivity analyses of the delay time $d$ to the performance level of the overall CSR $T$ and the optimal track of the corporate reputation $G$ of the supply chain is shown in Figure 3.
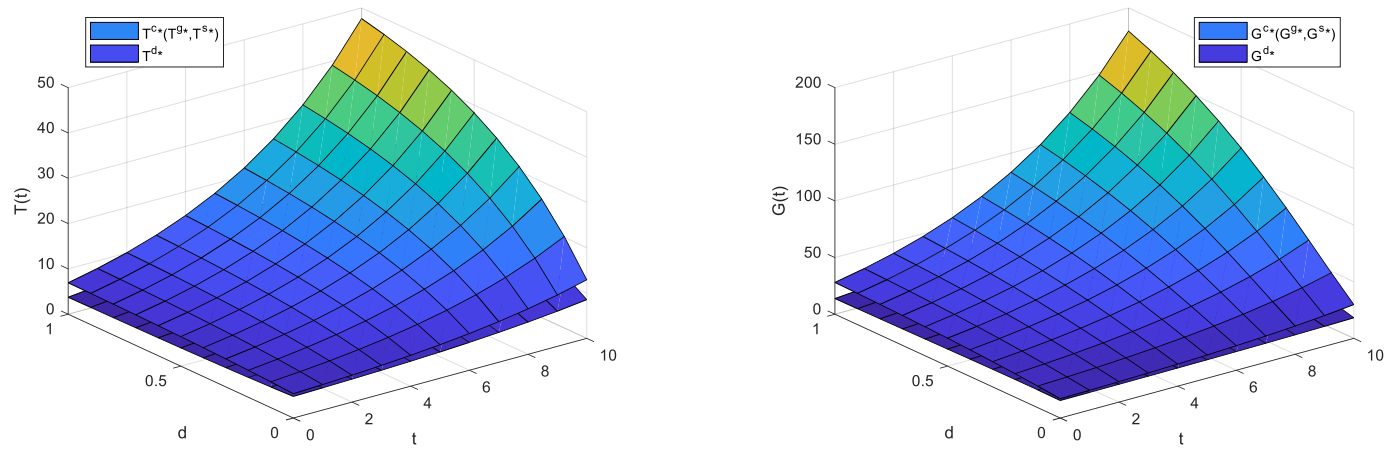

Figure 3. Effect of $d$ on the optimal trajectory of $T$ and $G$.

As can be seen from Figure 3, the performance level of CSR and the overall reputation of the supply chain rise over time. As the extension of the delay time gets longer, the two also go up.

(3) The sensitivity analysis of the delay time $d$ to the manufacturer's CSR effort $y_{m}$ and the overall supply chain profit $J_{s c}$ is shown in Figure 4.
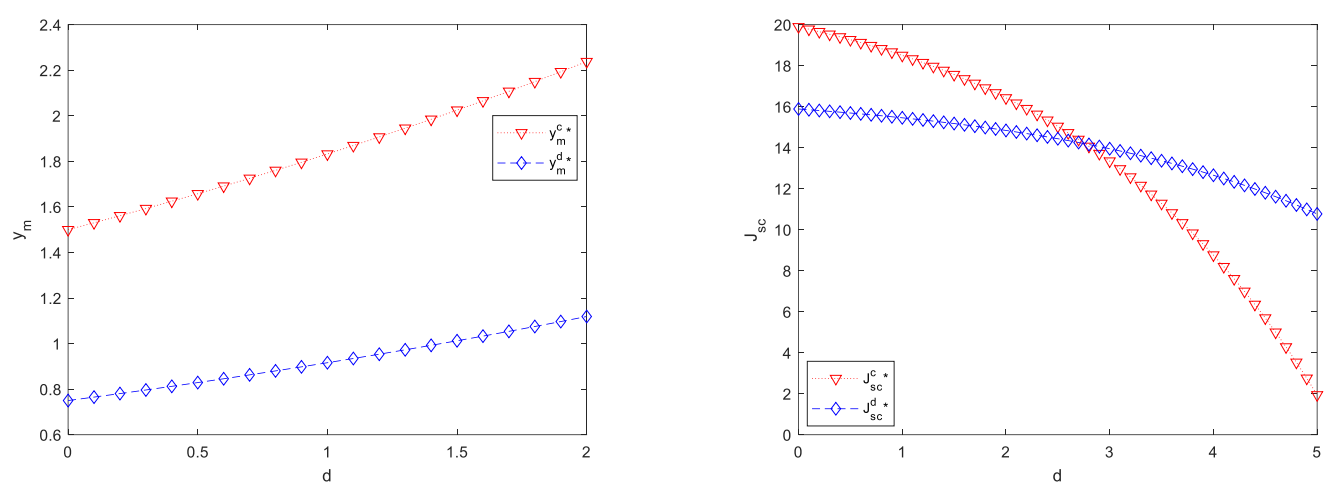

Figure 4. Effect of $d$ on $y_{m}$ and $J_{s c}$.

Figure 4 shows that the manufacturer's CSR efforts under the centralized supply chain decision-making mode are higher than those under the decentralized decision-making mode. As 
the delay time increases, the manufacturer's CSR efforts gradually increase (There is no graph to show the change trend here because the retailer's advertising efforts are not affected by the delay time). Under centralized supply chain decision-making mode, the overall profit of supply chain is far greater than that under decentralized decision-making mode. As the delay time increases, the overall profit of supply chain declines. Among them, the overall profit of supply chain under centralized decision-making mode is faster than that under decentralized decision-making mode. When the delay time is extended to about 2.80 , the overall profit of supply chain under centralized decision-making mode is lower than that under decentralized decision-making mode.

(4) The sensitivity analysis of government subsidy rate $S$ to the performance level of overall CSR and the optimal track of corporate reputation in the supply chain is as shown in Figures 5 and 6.

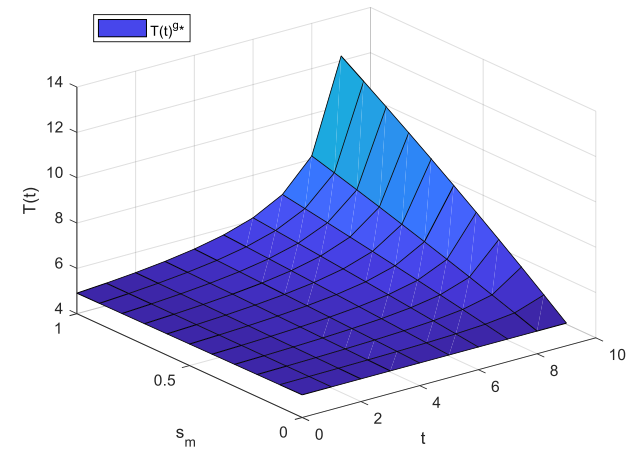

Figure 5. Effect of $s_{m}$ on the optimal trajectory of $T$.
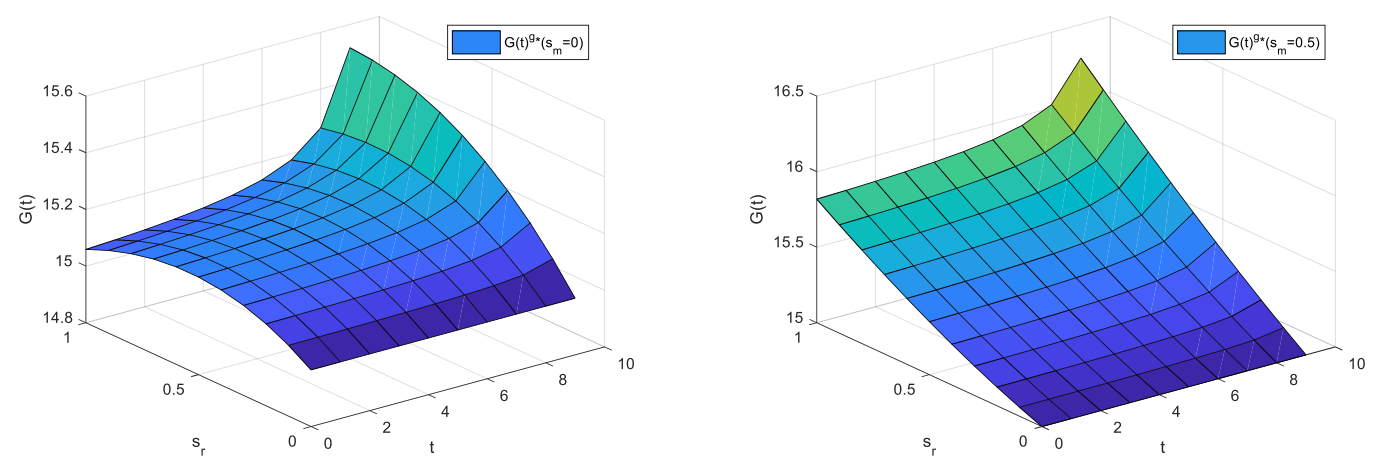

Figure 6. The influence of $s_{r}\left(s_{m}=0\right)$ and $s_{r}\left(s_{m}=0.5\right)$ on the optimal trajectory of $G$.

Figure 5 shows that the subsidy rate of government to manufacturers can promote the fulfillment level of CSR in supply chain, and the positive effect gets more obvious over time.

Figure 6 shows that, when the government subsidizes the retailers, it can promote the reputation of the supply chain. The incentive effect of government subsidy to manufacturers and retailers at the same time is better than that of single subsidy to retailers.

\section{Conclusions}

This paper takes the social responsibility of supply chain enterprises as the research object, taking into account the delayed effect of the fulfillment of CSR, and explores the incentive decisions to encourage the social responsibility of supply chain enterprises, based on the five scenarios of centralized supply chain decision-making, decentralized supply chain decision-making, decentralized supply chain decision-making under internal cooperation, decentralized supply chain decision-making under external cooperation, and decentralized supply chain decision-making under internal and external cooperation. The following conclusions are drawn. 
(1) By discussing the decision-making of centralized and decentralized supply chain, we can find that the decision-making of centralized supply chain has a higher level of a manufacturer's social responsibility and a retailer's advertising level than that of decentralized supply chain. A centralized supply chain comes with a relatively high overall profit and a relatively low retail price. Centralized decision-making mode is ideal in an actual society, yet is not easy to realize. In most cases, supply chains improve the overall performance by various means under decentralized decision-making.

(2) The delay time can promote the manufacturer's CSR effort level, the supply chain enterprise's social responsibility performance level, and the supply chain reputation. However, it has a certain negative effect on the overall profit of the supply chain.

(3) The delay time has a threshold value. If, and only if, it is less than the threshold value, the overall profit of supply chain under centralized decision-making mode is higher than that under decentralized decision-making mode.

(4) When the revenue-sharing coefficient and cost-sharing coefficient meet certain requirements, a mixed contract can perfectly coordinate the supply chain.

(5) The decision-maker of a supply chain can choose the mixed contract to coordinate a similar supply chain system without or with government subsidy.

(6) Government subsidies can promote the operation efficiency of decentralized supply chain decision-making. The level of fulfillment of CSR in supply chain can be improved by subsidizing manufacturers. While the goodwill of supply chain can be improved by subsidizing both manufacturers and retailers. The effect of multi-subsidy is better than that of single-subsidy.

As shown in the above conclusions, the delay time benefits the manufacturer's CSR efforts, the level of CSR, and reputation in the supply chain. However, it could hurt the economic performance of enterprises and cause investment waste when the delay time becomes too long. The cost of CSR increases and the supply chain's overall profit decreases as the delay time goes up. Therefore, manufacturers should try to shorten the delay time and reduce the delay effect. Secondly, the threshold of delay time should be considered in the internal collaboration of the supply chain. If the delay time is within this threshold, then a joint decision can be made in the supply chain, otherwise, it is not suitable. In addition, as an important stakeholder outside the supply chain, the government should strengthen the external governance capacity of the supply chain, using the government subsidy function to improve the enthusiasm of supply chain enterprises in fulfilling their social responsibilities, and ultimately play a positive role in the overall profits of the supply chain.

There are still some deficiencies in this study to be further explored and improved. This paper only discusses how to promote the decentralized supply chain to achieve the operation effect of the centralized supply chain, and does not analyze the optimal effect of the three incentive modes or compare the differences between them. Secondly, the research object of this paper is a simple two-echelon supply chain, which can be further studied in the future.

Author Contributions: Conceptualization, H.C. and H.D.; Formal analysis, H.C.; Funding acquisition, H.D.; Methodology, H.C.; Project administration, H.D.; Software, H.C.; Supervision, H.D.; Validation, H.C.; Writing—original draft, H.C.; Writing—review \& editing, H.C. and H.D. All authors have read and agreed to the published version of the manuscript.

Funding: This research was funded partly by the Social Science Planning Research Project of Shandong Province under grants 19CJJJ32, by the Research Project of Humanities and Social Sciences in Shandong Province under grant J18RB056.

Conflicts of Interest: The authors declare no conflict of interest.

\section{References}

1. Sheldon, O. The Philosophy of Management; Sir Isaac Pitman and Sons Ltd.: London, UK, 1924.

2. Bowen, H.R. Social Responsibilities of the Businessman; Harper: New York, NY, USA, 1953. 
3. Nematollahi, M.; Hosseini-Motlagh, S.-M.; Heydari, J. Coordination of social responsibility and order quantity in a two-echelon supply chain: A collaborative decision-making perspective. Int. J. Prod. Econ. 2017, 184, 107-121. [CrossRef]

4. Jokar, A.; Hosseini-Motlagh, S.M. Simultaneous coordination of order quantity and corporate social responsibility in a two-Echelon supply chain: A combined contract approach. J. Oper. Res. Soc. 2019, 1-16. [CrossRef]

5. Hosseini-Motlagh, S.M.; Govindan, K.; Nematollahi, M.; Jokar, A. An adjustable bi-level wholesale price contract for coordinating a supply chain under scenario-based stochastic demand. Int. J. Prod. Econ. 2019, 214, 175-195. [CrossRef]

6. Modak, N.M.; Kelle, P. Using social work donation as a tool of corporate social responsibility in a closed-loop supply chain considering carbon emissions tax and demand uncertainty. J. Oper. Res. Soc. 2019, 1-17. [CrossRef]

7. Modak, N.M.; Kazemi, N.; Cárdenas-Barrón, L.E. Investigating structure of a two-echelon closed-loop supply chain using social work donation as a Corporate Social Responsibility practice. Int. J. Prod. Econ. 2019, 207, 19-33. [CrossRef]

8. Hosseini-Motlagh, S.M.; Nouri-Harzvili, M.; Choi, T.M.; Ebrahimi, S. Reverse Supply Chain Systems Optimization with Dual Channel and Demand Disruptions: Sustainability, CSR Investment and Pricing Coordination. Inf. Sci. 2019, 503, 606-634. [CrossRef]

9. Ma, P.; Shang, J.; Wang, H. Enhancing corporate social responsibility: Contract design under information asymmetry. Omega 2017, 67, 19-30. [CrossRef]

10. Hsueh, C.F. Improving corporate social responsibility in a supply chain through a new revenue sharing contract. Int. J. Prod. Econ. 2014, 151, 214-222. [CrossRef]

11. Raza, S.A. Supply chain coordination under a revenue-sharing contract with corporate social responsibility and partial demand information. Int. J. Prod. Econ. 2018, 205, 1-14. [CrossRef]

12. Wu, C.H. Collaboration and sharing mechanisms in improving corporate social responsibility. Cent. Eur. J. Oper. Res. 2015, 24, 681-707. [CrossRef]

13. He, P.; He, Y.; Shi, C.; Xu, H.; Zhou, L. Cost-sharing contract design in a low-carbon service supply chain. Comput. Ind. Eng. 2019, 139, 106160. [CrossRef]

14. Cruz, J.M. Mitigating global supply chain risks through corporate social responsibility. Int. J. Prod. Res. 2013, 51, 3995-4010. [CrossRef]

15. Stranieri, S.; Orsi, L.; Banterle, A. Sustainable development and supply chain coordination: The impact of corporate social responsibility rules in the European Union food industry. Corp. Soc. Responsib. Environ. Manag. 2019, 26, 481-491. [CrossRef]

16. Yadav, R.S.; Dash, S.S.; Chakraborty, S.; Kumar, M. Perceived CSR and Corporate Reputation: The Mediating Role of Employee Trust. Vikalpa 2018, 43, 139-151. [CrossRef]

17. Tetrault Sirsly, C.-A.; Lvina, E. From Doing Good to Looking Even Better: The Dynamics of CSR and Reputation. Bus. Soc. 2016, 1-13. [CrossRef]

18. Hunter, M.L.; Van Wassenhove, L.N.; Besiou, M. Stakeholder Media: The Trojan Horse of Corporate Responsibility. Insead Work. Pap. Collect. 2009, 62, 1-30.

19. Taboubi, S. Incentive mechanisms for price and advertising coordination in dynamic marketing channels. Int. Trans. Oper. Res. 2017, 1-24. [CrossRef]

20. Buratto, A.; Cesaretto, R.; De Giovanni, P. Consignment contracts with cooperative programs and price discount mechanisms in a dynamic supply chain. Int. J. Prod. Econ. 2019, 218, 72-82. [CrossRef]

21. Lu, L.; Marín-Solano, J.; Navas, J. An Analysis of Efficiency of Time-consistent Coordination Mechanisms in a Model of Supply Chain Management. Eur. J. Oper. Res. 2019, 279, 211-224. [CrossRef]

22. Hafezalkotob, A.; Alavia, A.; Makui, A. Government financial intervention in green and regular supply chains: Multi-level game theory approach. Int. J. Manag. Sci. Eng. Manag. 2016, 11, 167-177. [CrossRef]

23. Zhang, Y.H.; Wang, Y. The impact of government incentive on the two competing supply chains under the perspective of Corporation Social Responsibility: A case study of Photovoltaic industry. J. Clean. Prod. 2017, 154, 102-113. [CrossRef]

24. Yi, Y.Y.; Li, J.X. The effect of governmental policies of carbon taxes and energy-saving subsidies on enterprise decisions in a two-echelon supply chain. J. Clean. Prod. 2018, 181, 675-691. [CrossRef] 
25. Arya, A.; Mittendorf, B. Supply Chain Consequences of Subsidies for Corporate Social Responsibility. Prod. Oper. Manag. 2015, 24, 1346-1357. [CrossRef]

26. Liu, Y.; Quan, B.; Xu, Q.; Forrest, J.Y.L. Corporate social responsibility and decision analysis in a supply chain through government subsidy. J. Clean. Prod. 2018, 208, 436-447. [CrossRef]

27. Carter, C.R.; Jennings, M.M. Social responsibility and supply chain relationships. Transp. Res. Part E Logist. Transp. Rev. 2002, 38, 37-52. [CrossRef]

28. Chiou, T.-Y.; Chan, H.K.; Lettice, F.; Chung, S.H. The influence of greening the suppliers and green innovation on environmental performance and competitive advantage in Taiwan. Transp. Res. Part E Logist. Transp. Rev. 2011, 47, 822-836. [CrossRef]

29. Zhao, X.; Li, N.; Song, L. Coordination of a socially responsible two-stage supply chain under random demand. Asia-Pac. J. Oper. Res. 2019, 36, 1-27. [CrossRef]

30. Machowska, D. Delayed effects of cooperative advertising in goodwill dynamics. Oper. Res. Lett. 2019, 47, 178-184. [CrossRef]

31. Nerlove, M.; Arrow, K.J. Optimal Advertising Policy under Dynamic Conditions. Economica 1962, $29,129$. [CrossRef]

32. Herbon, A.; Khmelnitsky, E. Optimal dynamic pricing and ordering of a perishable product under additive effects of price and time on demand. Eur. J. Oper. Res. 2017, 260, 546-556. [CrossRef]

33. Ouardighi, F.E. Supply quality management with optimal wholesale price and revenue sharing contracts: A two-stage game approach. Int. J. Prod. Econ. 2014, 156, 260-268. [CrossRef]

34. Basin, M.; Rodriguez-González, J. Optimal Control for Linear Systems with Multiple Time Delays in Control Input. IEEE. Trans. Autom. Control 2006, 51, 91-97. [CrossRef]

35. Zhou, Y.; Ye, X. Differential game model of joint emission reduction strategies and contract design in a dual-channel supply chain. J. Clean. Prod. 2018, 190, 592-607. [CrossRef]

(C) 2020 by the authors. Licensee MDPI, Basel, Switzerland. This article is an open access article distributed under the terms and conditions of the Creative Commons Attribution (CC BY) license (http://creativecommons.org/licenses/by/4.0/). 